\title{
Effect of molecular weight of polyethyleneimine on loading of CPG oligodeoxynucleotides onto flake-shell silica nanoparticles for enhanced TLR9-mediated induction of interferon- $\alpha$
}

\author{
This article was published in the following Dove Press journal: \\ International Journal of Nanomedicine \\ 13 July 2012 \\ Number of times this article has been viewed
}

\author{
Yuvaraj Manoharan ${ }^{1, *}$ \\ Qingmin $\mathrm{Ji}^{2}, *$ \\ Tomohiko Yamazaki ${ }^{2,3}$ \\ Shanmugavel Chinnathambi' \\ Song Chen ${ }^{2,4}$ \\ Singaravelu Ganesan' \\ Jonathan P Hill ${ }^{2}$ \\ Katsuhiko Ariga ${ }^{2,5}$ \\ Nobutaka Hanagata ${ }^{3,6}$ \\ 'Department of Medical Physics, \\ Anna University, Chennai, India; \\ ${ }^{2}$ Research Center for Materials \\ Nanoarchitectonics, National Institute \\ for Materials Science, Tsukuba, \\ lbarak, ${ }^{3}$ Graduate School of Life \\ Science, Hokkaido University, Kita-ku, \\ Sapporo, ${ }^{4}$ JSP Research Fellow, \\ Chiyoda-ku, Tokyo, ${ }^{5}$ JST and CREST, \\ National Institute for Materials \\ Science, Tsukuba, Ibaraki, Japan; \\ ${ }^{6}$ Nanotechnology Innovation Station, \\ National Institute for Materials \\ Science, Tsukuba, Ibaraki, Japan \\ *These authors contributed equally \\ to this work
}

\begin{abstract}
Background: Class B CpG oligodeoxynucleotides primarily interact with Toll-like receptor 9 (TLR9) in B cells and enhance the immune system through induction of various interleukins including interleukin-6 in these immune cells. Although free class B CpG oligodeoxynucleotides do not induce interferon (IFN)- $\alpha$ production, $\mathrm{CpG}$ oligodeoxynucleotide molecules have been reported to induce IFN- $\alpha$ when loaded onto nanoparticles. Here, we investigated the in vitro induction of IFN- $\alpha$ by a nanocarrier delivery system for class B $\mathrm{CpG}$ oligodeoxynucleotide molecules.
\end{abstract}

Methods: For improving the capacity to load $\mathrm{CpG}$ oligodeoxynucleotide molecules, flake-shell $\mathrm{SiO}_{2}$ nanoparticles with a specific surface area approximately 83-fold higher than that of smoothsurfaced $\mathrm{SiO}_{2}$ nanoparticles were prepared by coating $\mathrm{SiO}_{2}$ nanoparticles with polyethyleneimine (PEI) of three different number-average molecular weights (Mns 600, 1800, and 10,000 Da).

Results: The capacity of the flake-shell $\mathrm{SiO}_{2}$ nanoparticles to load $\mathrm{CpG}$ oligodeoxynucleotides was observed to be 5.8-fold to 6.7-fold higher than that of smooth-surfaced $\mathrm{SiO}_{2}$ nanoparticles and was found to increase with an increase in the Mn of the PEI because the Mn contributed to the positive surface charge density of the nanoparticles. Further, the flake-shell $\mathrm{SiO}_{2}$ nanoparticles showed much higher levels of IFN- $\alpha$ induction than the smooth-surfaced $\mathrm{SiO}_{2}$ nanoparticles. The highest IFN- $\alpha$ induction potential was observed for $\mathrm{CpG}$ oligodeoxynucleotide molecules loaded onto flake-shell $\mathrm{SiO}_{2}$ nanoparticles coated with PEI of Mn $600 \mathrm{Da}$, although the CpG oligodeoxynucleotide density was lower than that on flake-shell $\mathrm{SiO}_{2}$ nanoparticles coated with PEI of Mns 1800 and 10,000 Da. Even with the same density of CpG oligodeoxynucleotides on flake-shell $\mathrm{SiO}_{2}$ nanoparticles, PEI with an $\mathrm{Mn}$ of $600 \mathrm{Da}$ caused a markedly higher level of IFN- $\alpha$ induction than that with Mns of $1800 \mathrm{Da}$ and 10,000 Da. The higher TLR9-mediated IFN- $\alpha$ induction by $\mathrm{CpG}$ oligodeoxynucleotides on flake-shell $\mathrm{SiO}_{2}$ nanoparticles coated with a PEI of Mn $600 \mathrm{Da}$ is attributed to residence of the $\mathrm{CpG}$ oligodeoxynucleotide molecules in endolysosomes.

Keywords: $\mathrm{CpG}$ oligodeoxynucleotides, polyethyleneimine, Toll-like receptor 9, silica nanoparticles, delivery, interferon- $\alpha$

\section{Introduction}

$\mathrm{CpG}$ oligodeoxynucleotides can be used in immunotherapy for various illnesses, such as cancer, allergies/asthma, and infectious diseases. ${ }^{1-4}$ These molecules are effective because they elicit the immune system through their recognition by human Toll-like receptor 9 (TLR9), a molecule located in the endolysosomes of B cells and antigenpresenting cells, ${ }^{5}$ and thereby mediate innate and adaptive immune responses. ${ }^{6-8}$
Nanotechnology Innovation Station,

National Institute for Materials Science,

I-2-I Sengen, Tsukuba,

Ibaraki 305-0047, Japan

Tel +81298604774

Fax +81298592475

Email hanagata.nobutaka@nims.go.jp 
Synthetic CpG oligodeoxynucleotides can be divided into four classes on the basis of their structural features, which in turn are based on their sequences. Of these classes, class A and class B CpG oligodeoxynucleotides are well characterized. Class A $\mathrm{CpG}$ oligodeoxynucleotides form self-assembled higher-order structures because of an internal palindromic sequence and polyguanine sequences at the $5^{\prime}$ and $3^{\prime}$ ends. ${ }^{9,10}$ Class B CpG oligodeoxynucleotides are thought to have a linear structure because the characteristic sequences required to form higher-order structures are lacking in these molecules. Of importance, cytokine induction by $\mathrm{CpG}$ oligodeoxynucleotides is dependent on these class distinctions. In particular, class A $\mathrm{CpG}$ oligodeoxynucleotides primarily activate TLR9 in plasmacytoid dendritic cells and cause induction of interferon (IFN)- $\alpha,{ }^{11-13}$ whereas class B CpG oligodeoxynucleotides stimulate TLR9 in B cells to induce interleukin (IL)-6. ${ }^{12-16}$ Class A and class B CpG oligodeoxynucleotides have a phosphorothioate backbone to minimize degradation by nucleases. However, this phosphorothioate backbone is associated with various side effects. ${ }^{17-20}$ Recently, we reported a nuclease-resistant $\mathrm{CpG}$ oligodeoxynucleotide that consists entirely of a natural phosphodiester backbone. ${ }^{21}$ This $\mathrm{CpG}$ oligodeoxynucleotide, referred to as CpG ODN2006x3-PD, does not have the potential to form higher-order structures and stimulates IL-6 induction.

Delivery of $\mathrm{CpG}$ oligodeoxynucleotide molecules using nanoparticles has been studied because this delivery system has several advantages relative to administration of free $\mathrm{CpG}$ oligodeoxynucleotide molecules, including protection of the CpG oligodeoxynucleotide molecules from degradation by nucleases, ${ }^{22,23}$ improvement of cellular uptake efficiency, ${ }^{24,25}$ and delivery to target tissues. ${ }^{26,27}$ Moreover, this delivery system has the potential to increase the number of cytokines that can be induced by different $\mathrm{CpG}$ oligodeoxynucleotides. For instance, the linear structured class B CpG ODN2007 molecules loaded onto the surface of cationic polystyrene nanoparticles with a diameter of $180 \mathrm{~nm}$ can stimulate IFN- $\alpha$ induction, ${ }^{9}$ whereas free CpG ODN2007 molecules have no such potential. This finding implies that nanoparticles can influence signal transduction through TLR9. In a preliminary experiment, CpG ODN2006x3-PD molecules loaded onto the surface of cationic polystyrene nanoparticles with a diameter of $500 \mathrm{~nm}$ also induced IFN- $\alpha$. The capacity to load $\mathrm{CpG}$ oligodeoxynucleotide molecules onto the surface of nanoparticles is thought to be a crucial factor in the enhancement of IFN- $\alpha$ induction.

$\mathrm{SiO}_{2}$ nanoparticles are a candidate carrier for nucleic acid-based drugs because of their large surface area and pore volume, biocompatibility, and ease of surface functionalization. ${ }^{28-30}$ Because $\mathrm{SiO}_{2}$ nanoparticles possess a negative charge, prefunctionalization by addition of amino groups or by coating with polycations is required to bind negatively charged nucleic acid drugs. However, such surface prefunctionalization negates the advantages of the mesopores in mesoporous $\mathrm{SiO}_{2}$ nanoparticles. Therefore, we developed novel $\mathrm{SiO}_{2}$ nanoparticles, referred to as flakeshell $\mathrm{SiO}_{2}$ nanoparticles, which possess a large surface area similar to that of mesoporous $\mathrm{SiO}_{2}$ nanoparticles. ${ }^{31}$ To bind the $\mathrm{CpG}$ oligodeoxynucleotide molecules electrostatically to the flake-shell $\mathrm{SiO}_{2}$ nanoparticles, we coated the surface of the flake-shell $\mathrm{SiO}_{2}$ nanoparticles with the synthetic cationic polymer polyethyleneimine (PEI) of different number-average molecular weights (Mns). PEI is used alone as a vehicle for nucleic acid delivery, but it can also be used for surface coating of nanoparticles to bind negatively charged nucleic acid drugs. ${ }^{32-34}$ Surface-coated high molecular weight PEI has been reported to permit high gene transfection efficiency and gene knockdown efficiency in plasmid and siRNA delivery, respectively; however, high molecular weight PEI is also toxic. ${ }^{28}$ In contrast, low molecular weight PEI is not toxic, but is ineffective for gene transfection and knockdown. Thus, the Mn of PEI is a critical factor in nucleic acid drug delivery.

This paper presents the advantages of flake-shell $\mathrm{SiO}_{2}$ nanoparticles compared with smooth-surfaced $\mathrm{SiO} 2$ nanoparticles, and reports optimization of the surface coating of flake-shell $\mathrm{SiO}_{2}$ nanoparticles by PEI for IFN- $\alpha$ induction through interaction between CpG ODN2006x3-PD molecules and TLR9.

\section{Materials and methods Preparation and characterization of flake-shell $\mathrm{SiO}_{2}$ nanoparticles}

Flake-shell silica spheres were prepared using a dissolution-regrowth process. ${ }^{31}$ Typically, $500 \pm 20 \mathrm{~nm}$ silica particles $(150 \mathrm{mg})$ were dispersed in $5 \mathrm{~mL}$ of water and then heated to $75^{\circ} \mathrm{C}$ in the presence of $\mathrm{NaBH}_{4}(0.5 \mathrm{~g})$ in a $20 \mathrm{~mL}$ Teflon-lined autoclave for 24 hours. Subsequently, the samples were collected by centrifugation and rinsed with pure water. Smooth-surfaced $\mathrm{SiO}_{2}$ nanoparticles with an average size of $500 \mathrm{~nm}$ were purchased from Polysciences Inc (Warrington, PA).

Field-emission scanning electron microscopy was performed using a Hitachi S-4800 operating at an acceleration voltage of $10 \mathrm{kV}$ or $30 \mathrm{kV}$. Nitrogen adsorption and desorption isotherm measurements were performed on powdered samples with a micrometrics-accelerated surface area at $77 \mathrm{~K}$. 
The specific surface area was calculated from the adsorption branch using the Brunauer-Emmett-Teller model. The surface charge of the nanoparticles was measured using a laser electrophoresis zeta-potential analyzer (LEZA-600, Otuka, Japan).

\section{Preparation of $\mathrm{PEI}$-coated $\mathrm{SiO}_{2}$ nanoparticles}

PEI with average Mns of 600, 1800, and 10,000 Da (PEI-600, PEI-1800, PEI-10,000) was purchased from Wako Pure Chemicals (Osaka, Japan) and diluted with ethanol to a concentration of $3 \%(\mathrm{v} / \mathrm{v})$ prior to use. For surface coating, $1 \mathrm{mg}$ of the $\mathrm{SiO}_{2}$ nanoparticles was suspended in $1.5 \mathrm{~mL}$ of $3 \%$ PEI. The suspension was shaken at room temperature for 6 hours, and the PEI-coated $\mathrm{SiO}_{2}$ nanoparticles were subsequently collected by centrifugation at 15,000 rpm for 15 minutes. After five washes with pure water, the PEIcoated $\mathrm{SiO}_{2}$ nanoparticles were dried in an incubator at $37^{\circ} \mathrm{C}$ overnight. The powdered $\mathrm{SiO}_{2}$ nanoparticles coated with PEI were resuspended in phosphate-buffered saline at a concentration of $1 \mathrm{mg} / \mathrm{mL}$.

Scanning transmission electron microscopy was performed using a Hitachi S-4800 microscope operating at an accelerating voltage of $30 \mathrm{kV}$. Thermogravimetric analysis measurements were obtained on an SII TG/DTA 6200 system at a heating rate of $5^{\circ} \mathrm{C}$ per minute. Dynamic light scattering was performed on a Delsa ${ }^{\mathrm{TM}}$ Nano analyzer. The Mn and polydispersity index of the PEI were measured on a Shodex GPC-101 system (Showa Denko, Tokyo, Japan) with a Shodex OHpak SB-810-HQ column and a RI-71S refractive index detector. The solvent was $0.3 \mathrm{M}$ sodium acetate/acetic acid buffer ( $\mathrm{pH} 4.4$ ), and the flow rate was $0.8 \mathrm{~mL} / \mathrm{minute}$.

\section{Preparation of $C_{p} G$ oligodeoxynucleotide-loaded $\mathrm{SiO}_{2}$ nanoparticles}

The 72-mer natural phosphodiester CpG ODN2006x3-PD (5'-TCGTCGTTTTGTCGTTTTGTCGTTTCGTCGTTT TGTCGTTTTGTCGTTTCGTCGTTTTGTCGTTTTGTC GTT-3'; Fasmac Inc, Kanagawa, Japan) was diluted with sterilized water to concentrations of about $200 \mu \mathrm{M}$. The CpG ODN2006x3-PD solution $(6 \mu \mathrm{L})$ was added to $40 \mu \mathrm{L}$ of $1 \mathrm{mg} / \mathrm{mL}$ PEI-coated $\mathrm{SiO}_{2}$ nanoparticles and then shaken at room temperature for one hour. The mixture was centrifuged at 15,000 rpm for 15 minutes to collect $\mathrm{SiO}_{2}$ nanoparticles loaded with CpG ODN2006x3-PD molecules. The loading capacity was calculated from the concentration of unloaded $\mathrm{CpG}$ oligodeoxynucleotide molecules in the supernatant using a NanoDrop spectrophotometer (Thermo Fisher Scientific Inc, Waltham, MA).

\section{Cytotoxicity assay}

The cytotoxicity of PEI-coated $\mathrm{SiO}_{2}$ nanoparticles was assessed using a Cell Counting Kit-8 (Dojindo, Kumamoto, Japan). Peripheral blood mononuclear cells (Cellular Technology Limited, Cleveland, $\mathrm{OH}$ ) were seeded in a 96-well plate at a density of 5000 cells per well and exposed to PEI-coated $\mathrm{SiO}_{2}$ nanoparticles at various concentrations (about $100 \mu \mathrm{g} / \mathrm{mL}$ ). RPMI 1640 medium supplemented with 10\% fetal bovine serum was used for the culture. After 48 hours, $10 \mu \mathrm{L}$ of CCK-8 was added to each well and incubated for 2 hours. The absorbance at $450 \mathrm{~nm}$ was measured using a microplate reader (MTP-880 Lab, Corona Electric, Ibaraki, Japan) to evaluate formazan formation from water-soluble tetrazolium salt due to mitochondrial dehydrogenase activity.

\section{Cytokine assay}

Peripheral blood mononuclear cells were seeded in $190 \mu \mathrm{L}$ of RPMI 1640 medium supplemented with $10 \%$ fetal bovine serum, at a density of $5 \times 10^{6}$ cells $/ \mathrm{mL}$. The cells were immediately stimulated with $10 \mu \mathrm{L}$ of $1 \mathrm{mg} / \mathrm{mL} \mathrm{SiO}_{2}$ nanoparticles loaded with CpG-ODN2006x3-PD molecules in a 96-well culture plate (Greiner Bio-One Co, Ltd, Tokyo, Japan). For the controls, free CpG ODN2116 and CpG ODN2006x3-PD molecules were added into the culture medium at elevated concentrations. After 48 hours of incubation at $37^{\circ} \mathrm{C}$, the supernatants were collected, and the level of IFN- $\alpha$ in the medium was determined by enzyme-linked immunosorbent assay using the Human IFN-Module enzyme-linked immunosorbent assay set (eBiosciences, Vienna, Austria).

\section{Results \\ Characterization of flake-shell $\mathrm{SiO}_{2}$ nanoparticles for loading $C_{p G}$ oligodeoxynucleotides}

Flake-shell $\mathrm{SiO}_{2}$ nanoparticles were prepared using a dissolution-regrowth process. ${ }^{31}$ The diameter of the flake-shell $\mathrm{SiO}_{2}$ nanoparticles was about $600 \mathrm{~nm}$ (Figure 1A), and the surface consisted of a network of thin flakes with a layer thickness of 60-80 nm (Figure 1B). The $\mathrm{SiO}_{2}$ nanoparticles used in this study were found to have a Brunauer-EmmettTeller-specific surface area of $656 \mathrm{~m}^{2} / \mathrm{g}$ (Figure 1C), which was significantly greater than the surface area $\left(7.89 \mathrm{~m}^{2} / \mathrm{g}\right)$ of commercially available smooth-surfaced $\mathrm{SiO}_{2}$ nanoparticles with a diameter of $500 \mathrm{~nm}$. 
A

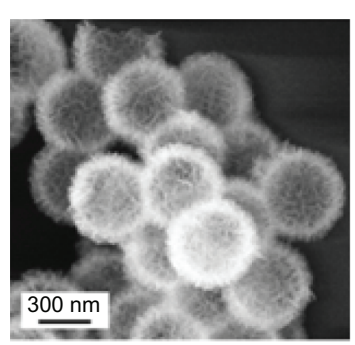

B

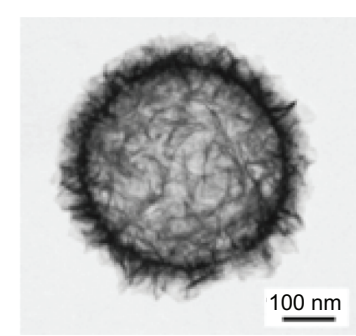

C

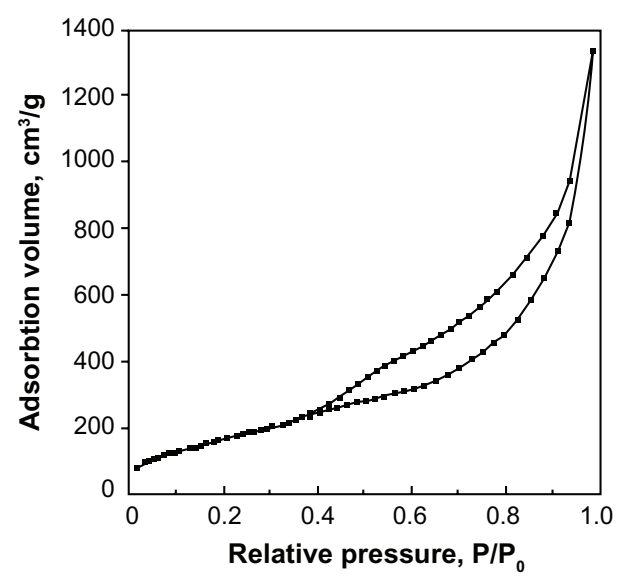

Figure I Characterization of flake-shell $\mathrm{SiO}_{2}$ nanoparticles. (A) Field-emission scanning electron microscopy image. (B) Scanning transmission electron microscopic image. (C) Nitrogen adsorption-desorption isotherms.

For binding negatively charged $\mathrm{CpG}$ oligodeoxynucleotides to the $\mathrm{SiO}_{2}$ nanoparticles, the surface of the $\mathrm{SiO}_{2}$ nanoparticles was coated with PEI of three different Mns $(600,1800$, and 10,000$)$. The polydispersity indexes were 1.12, 1.15, and 1.41 for PEI-600, PEI-1800, and PEI-10,000, respectively. The surface charge of the flake-shell $\mathrm{SiO}_{2}$ nanoparticles was observed to depend on the Mn of the PEI (Table 1), showing a higher positive charge density with an increase in Mn of the PEI.

The scanning transmission electron microscopic images of the flake-shell $\mathrm{SiO}_{2}$ nanoparticles before and after being coated with PEI of different Mns showed no obvious changes in the shell morphology (Figure 2A). The thickness of the PEI on the surface was difficult to distinguish because of the rough and irregular shell network. However, by carefully comparing high-contrast images, we could find PEI that covered the surface of the $\mathrm{SiO}_{2}$ nanoparticles. The size distribution of the $\mathrm{SiO}_{2}$ nanoparticles lacking a PEI coating showed a maximum diameter at $601 \mathrm{~nm}$ and a polydispersity index of 0.26 , as measured using dynamic light scattering (Figure 2B). The PEI coating on the surface may have resulted in partial aggregation of the flake-shell $\mathrm{SiO}_{2}$ nanoparticles. The scattering profiles showed major peaks centered around $673 \mathrm{~nm}, 1080 \mathrm{~nm}$, and $1330 \mathrm{~nm}$ for the $\mathrm{SiO}_{2}$ nanoparticles coated with PEI-600, PEI-1800, and PEI-10,000, respectively (Figure 2B). Moreover, the polydispersity indexes were 0.36 , 0.37 , and 0.13 for the flake-shell $\mathrm{SiO}_{2}$ nanoparticles coated with PEI-600, PEI-1800, and PEI-10,000, respectively. The amount of coverage by the PEI in the $\mathrm{SiO}_{2}$ nanoparticles was determined on the basis of thermogravimetric analysis. The PEI/silica $(\mathrm{w} / \mathrm{w})$ coverage ratios were estimated to be 0.33, 0.30, and 0.51 for PEI-600, PEI-1800, and PEI-10,000, respectively (Figure 2C).

The $\mathrm{N}_{2}$ adsorption-desorption isotherms showed that the BET-specific surface areas of the flake-shell $\mathrm{SiO}_{2}$ nanoparticles after coating with PEI-600, PEI-1800, and PEI-10,000 were 79,92 , and $73 \mathrm{~m}^{2} / \mathrm{g}$, respectively (Figure 2D). These specific surface areas were $11 \%-14 \%$ of those of naked flakeshell $\mathrm{SiO}_{2}$ nanoparticles but were still 9.2-11.6 times higher than that of smooth-surfaced $\mathrm{SiO}_{2}$ nanoparticles.

\section{Cytotoxicity of flake-shell $\mathrm{SiO}_{2}$ nanoparticles}

We tested the cytotoxicity of PEI-coated $\mathrm{SiO}_{2}$ nanoparticles in peripheral blood mononuclear cells using the water-soluble

Table I Surface charge and maximum loading capacity of $\mathrm{Cp}_{\mathrm{PG}} \mathrm{ODNs}$ on $\mathrm{SiO}_{2}$ nanoparticles coated with PEls of different number-average molecular weights

\begin{tabular}{|c|c|c|c|}
\hline & \multicolumn{2}{|c|}{ Zeta potential $(\mathrm{mV})$} & \multirow{2}{*}{$\begin{array}{l}\text { Maximum loading capacity } \\
\text { for CpG ODNs } \\
\text { ( } \mu \mathrm{g} / \mathrm{mg} \text { nanoparticles) }\end{array}$} \\
\hline & $\begin{array}{l}\text { Before loading of } \\
\text { CpG ODNs }\end{array}$ & $\begin{array}{l}\text { After loading of } \\
\text { CpG ODNs }\end{array}$ & \\
\hline \multicolumn{4}{|c|}{ Smooth-surfaced $\mathrm{SiO}_{2}$ nanoparticles coated with $3 \% \mathrm{PEI}$ and } \\
\hline$M n=600$ & $6.9 \pm 1.8$ & $-23.3 \pm 3.7$ & $17.9 \pm 2.4$ \\
\hline$M n=1800$ & $10.3 \pm 1.2$ & $-26.1 \pm 4.9$ & $31.5 \pm 2.5$ \\
\hline$M n=10,000$ & $17.8 \pm 1.3$ & $-27.4 \pm 2.3$ & $49.3 \pm 1.3$ \\
\hline \multicolumn{4}{|c|}{ Flake-shell $\mathrm{SiO}_{2}$ nanoparticles coated with $3 \%$ PEls with } \\
\hline$M n=600$ & $5.4 \pm 0.7$ & $-24.1 \pm 3.4$ & $97.7 \pm 11.5$ \\
\hline$M n=1800$ & $8.4 \pm 1.0$ & $-27.1 \pm 4.4$ & $180.7 \pm 13.0$ \\
\hline$M n=10,000$ & $11.9 \pm 1.7$ & $-31.2 \pm 5.7$ & $321.0 \pm 12.0$ \\
\hline
\end{tabular}

Abbreviations: $\mathrm{Mn}$, number-average molecular weight; $\mathrm{SiO}_{2}$, mesoporous silica; $\mathrm{ODN}$, oligodeoxynucleotides; $\mathrm{PEI}$, polyethyleneimine. 
A
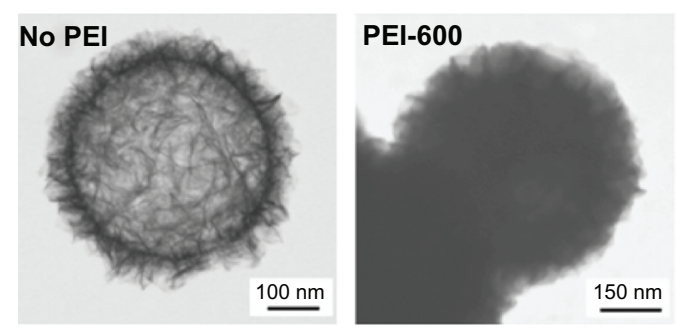

B
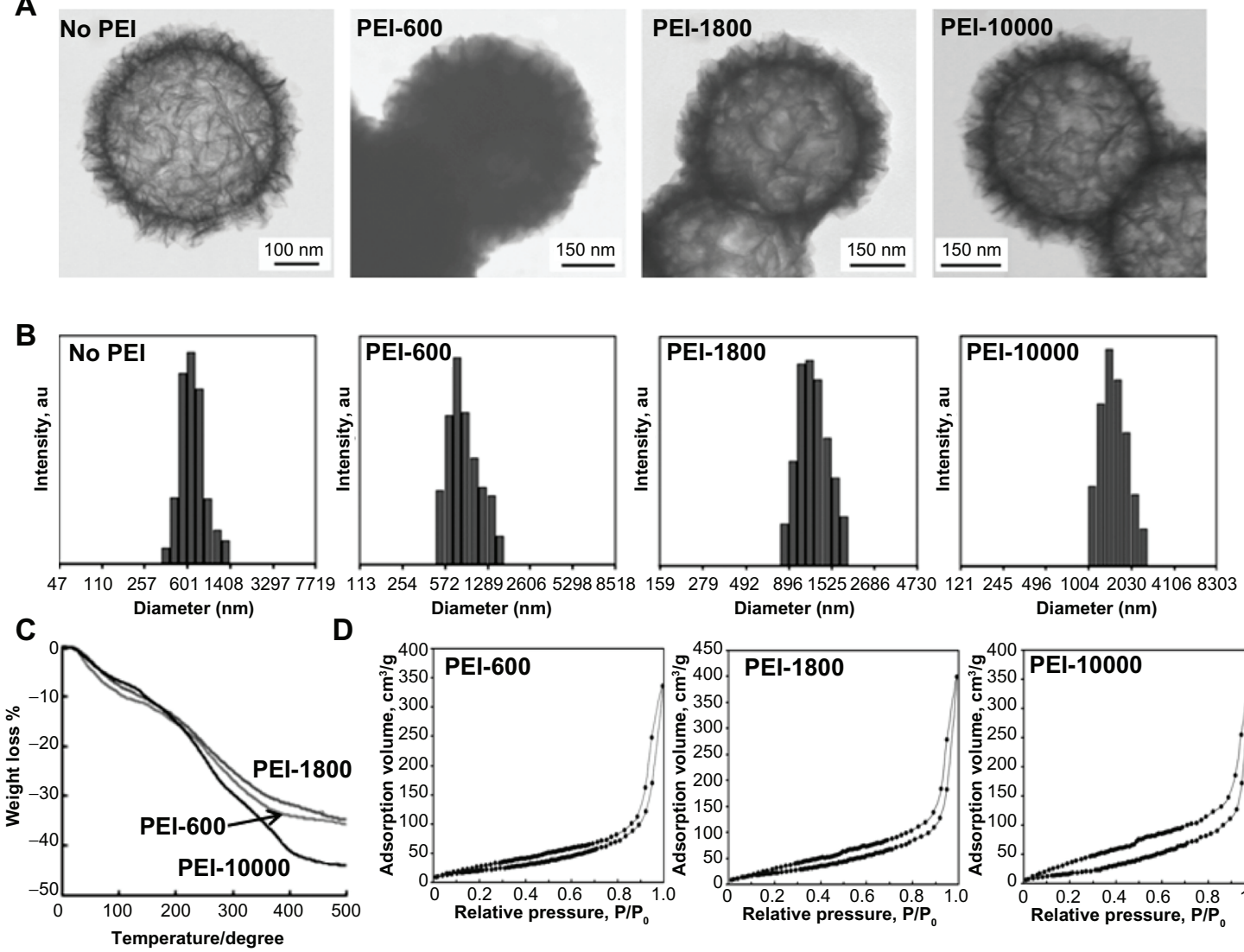

Figure 2 Characterization of flake-shell $\mathrm{SiO}_{2}$ nanoparticles coated with PEI-600, PEI-1800, and PEI-10,000. (A) Scanning transmission electron microscopic images of flake-shell $\mathrm{SiO}_{2}$ nanoparticles before and after coating with PEl. (B) Particle size distribution of flake-shell $\mathrm{SiO}_{2}$ nanoparticles measured using dynamic light scattering. The polydispersity index was 0.26 for the $\mathrm{SiO}_{2}$ nanoparticles without PEI. The polydispersity index was $0.36,0.37$, and 0.13 for PEI-600, PEI- I800, and PEI-I0,000, respectively. (C) Thermogravimetric analysis of flake-shell $\mathrm{SiO}_{2}$ nanoparticles coated with PEl. (D) $\mathrm{N}_{2}$ adsorption-desorption isotherms of flake-shell $\mathrm{SiO}_{2}$ nanoparticles after coating with PEl.

Abbreviation: PEI, polyethyleneimine.

tetrazolium cell proliferation assay in which peripheral blood mononuclear cells were exposed to PEI-coated $\mathrm{SiO}_{2}$ nanoparticles for 48 hours. No cytotoxicity was observed for smooth-surfaced $\mathrm{SiO}_{2}$ nanoparticles coated with PEI of any Mn (Figure 3A). In contrast, when the cells were exposed to flake-shell $\mathrm{SiO}_{2}$ nanoparticles coated with PEI at concentrations greater than $75 \mu \mathrm{g} / \mathrm{mL}$, the cell viability was less than $90 \%$ that of control cells (Figure 3B). Thus, flake-shell $\mathrm{SiO}_{2}$ nanoparticles were safe at concentrations less than $50 \mu \mathrm{g} / \mathrm{mL}$. The Mn of PEI did not affect the cytotoxicity.

\section{Capacity of $\mathrm{SiO}_{2}$ nanoparticles to load CpG ODN2006×3-PD}

Next, we examined the maximum capacity of PEI-coated $\mathrm{SiO}_{2}$ nanoparticles to load $\mathrm{CpG}$ oligodeoxynucleotide molecules. As expected, the maximum capacity for loading CpG ODN2006x3-PD molecules increased with an increase in the Mn of PEI in both smooth-surfaced and flake-shell $\mathrm{SiO}_{2}$ nanoparticles (Figure 4 and Table 1) because the $\mathrm{SiO}_{2}$ nanoparticles coated with PEI of a higher Mn had a higher positive charge density (Table 1). The maximum capacity of flake-shell $\mathrm{SiO}_{2}$ nanoparticles coated with PEI-600, PEI-1800, and PEI-10,000 to load CpG ODN2006x3-PD molecules was $97.7 \pm 11.5,180.7 \pm 13.0$, and $321 \pm 12.3 \mu \mathrm{g} / \mathrm{mg}$ nanoparticles, respectively (Table 1 ). These capacities were 5.8-6.7 times higher than those of smooth-surfaced $\mathrm{SiO}_{2}$ nanoparticles. However, the specific surface area of the flakeshell $\mathrm{SiO}_{2}$ nanoparticles was about 83 -fold higher than that of the smooth-surfaced $\mathrm{SiO}_{2}$ nanoparticles. This low capacity is thought to be the result of a decrease in the specific surface area caused by coating of the surface with PEI because this molecule can penetrate the open spaces between flakes. After the loading of CpG ODN2006x3-PD molecules onto $\mathrm{SiO}_{2}$ nanoparticles coated with PEI, the amount of CpG ODN2006x3-PD molecules released from the $\mathrm{SiO}_{2}$ nanoparticles was tested under acidic conditions corresponding to the physiological environment in the TLR9-localized endolysosome. However, no CpG ODN2006x3-PD molecules were released from the $\mathrm{SiO}_{2}$ nanoparticles (data not shown). 

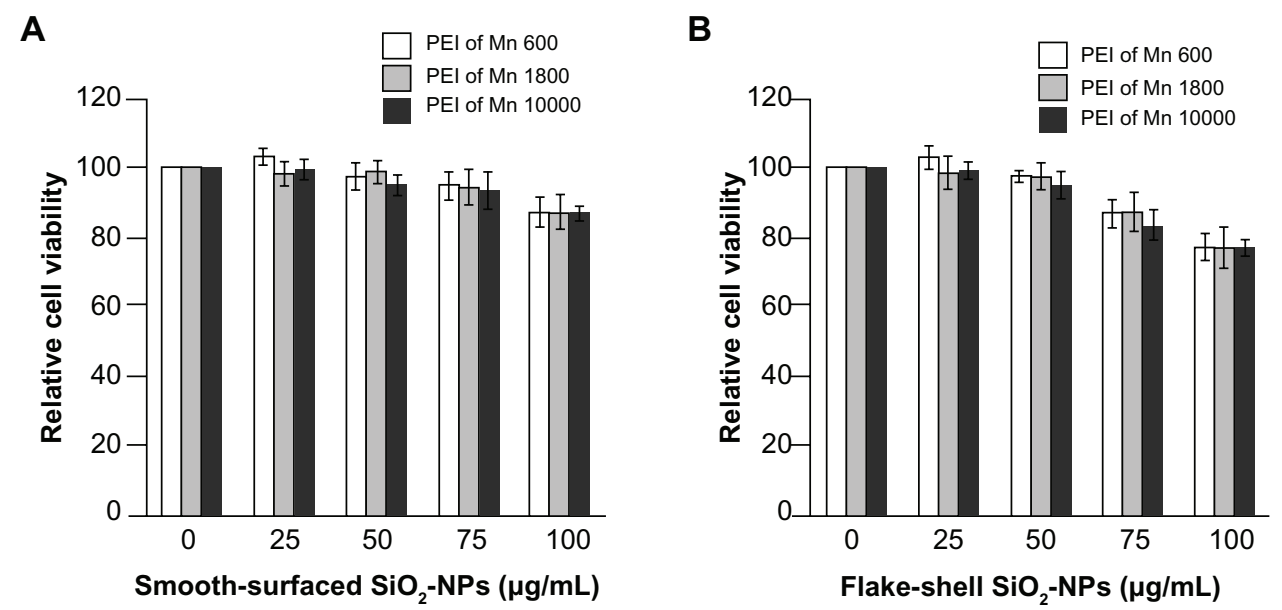

Figure 3 Cytotoxicity of PEl-coated $\mathrm{SiO}_{2}$ nanoparticles. Relative cell viability of smooth-surfaced (A) and flake-shell (B) $\mathrm{SiO}_{2}$ nanoparticles coated with PEl of Mns 600 , I800, and 10,000. Peripheral blood mononuclear cells were exposed to PEl-coated $\mathrm{SiO}_{2}$ nanoparticles at various concentrations for 48 hours. Abbreviations: PEl, polyethyleneimine, NPs, nanoparticles; Mn, number-average molecular weight.

\section{Stimulation of IFN- $\alpha$ induction}

To investigate IFN- $\alpha$ induction by $\mathrm{CpG}$ ODN2006x3-PD molecules loaded onto the $\mathrm{SiO}_{2}$ nanoparticles, $50 \mu \mathrm{g} / \mathrm{mL}$ of $\mathrm{SiO}_{2}$ nanoparticles loaded with a maximum amount of CpG ODN2006x3-PD molecules were applied to peripheral blood mononuclear cells. Free CpG ODN2216 (class A CpG oligodeoxynucleotide) molecules stimulated IFN- $\alpha$ induction in a dose-dependent manner (Figure 5A). Although free CpG ODN2006x3-PD molecules did not induce IFN- $\alpha$ at any concentration (Figure 5A), the $\mathrm{CpG}$ oligodeoxynucleotide molecules on the $\mathrm{SiO}_{2}$ nanoparticles induced IFN- $\alpha$ at all the Mns examined (Figure 5B). If all the CpG ODN2006x3-PD molecules were released from the $\mathrm{SiO}_{2}$ nanoparticles into the culture medium, the concentrations of CpG ODN2006x3-PD would be predicted to be 196,364 , and $650 \mathrm{pmol} / \mathrm{mL}$ for the flake-shell $\mathrm{SiO}_{2}$ nanoparticles coated with PEI-600, PEI-1800, and PEI-10,000, respectively. The CpG ODN2006x3-PD molecules on the flake-shell $\mathrm{SiO}_{2}$ nanoparticles coated with
PEI-600 and PEI-1800 would have a much higher potential to stimulate IFN- $\alpha$ than the same concentration of free class A CpG ODN2216 molecules. Similarly, CpG ODN2006x3-PD molecules on smooth-surfaced $\mathrm{SiO}_{2}$ nanoparticles would also be predicted to have a higher capacity to induce IFN- $\alpha$ than the same concentration of free class A CpG ODN2216 molecules because the concentrations of CpG ODN2006x3-PD molecules would be 33,62 , and $98 \mathrm{pmol} / \mathrm{mL}$ if all the $\mathrm{CpG}$ ODN2006x3-PD molecules were released from smoothsurfaced $\mathrm{SiO}_{2}$ nanoparticles coated with PEI-600, PEI-1800, and PEI-10,000, respectively. When the PEI for the surface coating was examined at the same $\mathrm{Mn}$, the IFN- $\alpha$ induction was higher for flake-shell $\mathrm{SiO}_{2}$ nanoparticles than for smooth-surfaced $\mathrm{SiO}_{2}$ nanoparticles, probably because of the higher capacity of flake-shell $\mathrm{SiO}_{2}$ nanoparticles to load $\mathrm{CpG}$ ODN2006x3-PD molecules. However, among the flake-shell $\mathrm{SiO}_{2}$ nanoparticles, the PEI-600-coated $\mathrm{SiO}_{2}$ nanoparticles showed higher IFN- $\alpha$ induction than those coated with
A

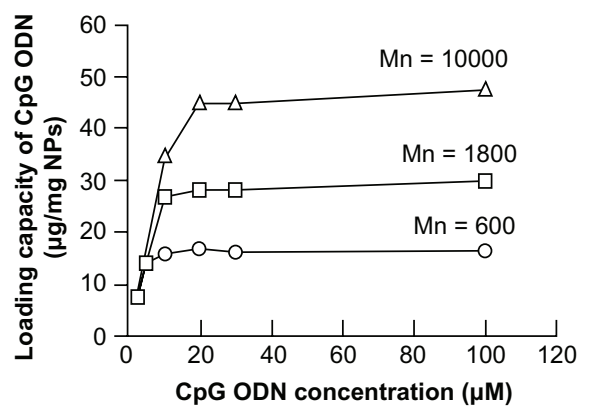

B

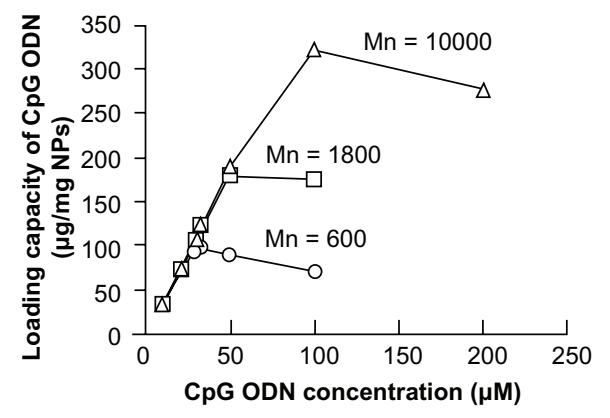

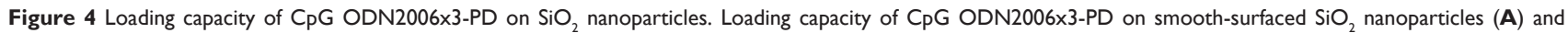
flake-shell $\mathrm{SiO}_{2}$ nanoparticles (B) coated with polyethyleneimine of Mns 600, 1800, and 10,000. CpG ODN2006×3-PD solutions (46 $\mu \mathrm{L}$ ) of various concentrations were incubated with $40 \mu \mathrm{g}$ of $\mathrm{SiO}_{2}$ nanoparticles coated with polyethyleneimine.

Abbreviations: PEI, polyethyleneimine; NPs, nanoparticles; Mn, number-average molecular weight; ODN, oligodeoxynucleotides. 
A

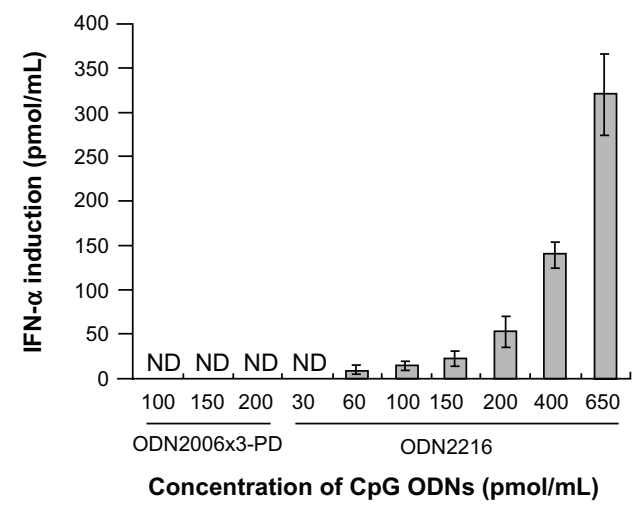

B

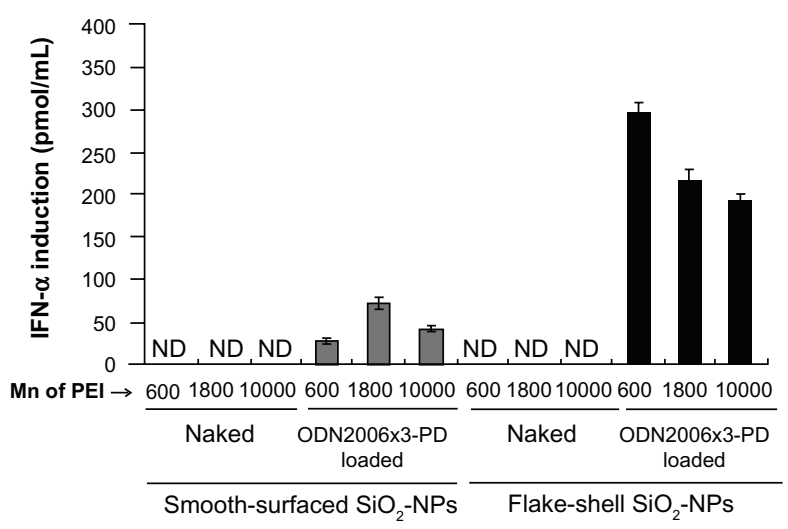

Figure 5 IFN- $\alpha$ induction by $C_{P G}$ ODNs in peripheral blood mononuclear cells. (A) IFN- $\alpha$ induction by free CPG ODN2006x3-PD and CpG ODN22I6. Free class A CPG ODN2216 induced IFN- $\alpha$ in a dose-dependent manner, but free CpG ODN2006×3-PD did not induce IFN- $\alpha$. (B) IFN- $\alpha$ induction by CpG ODN2006×3-PD loaded on $\mathrm{SiO}_{2}$ nanoparticles. Naked smooth-surfaced and flake-shell $\mathrm{SiO}_{2}$ nanoparticles did not induce IFN- $\alpha$, but CpG ODN2006x3-PD loaded on smooth-surfaced and flake-shell $\mathrm{SiO}_{2}$ nanoparticles coated with PEl induced IFN- $\alpha$. The $\mathrm{SiO}_{2}$ nanoparticles loaded with CpG ODN2006x3-PD were applied to peripheral blood mononuclear cells at a concentration of $50 \mu \mathrm{g} / \mathrm{mL}$. The concentrations of CPG ODN2006x3-PD on smooth-surfaced SiO ${ }_{2}$ nanoparticles coated with PEI of Mns 600, I800, and I0,000 were estimated to be 33,62 , and $98 \mathrm{pmol} / \mathrm{mL}$ medium, respectively, from the loading capacities. Similarly, the concentrations of $\mathrm{CpG}_{\mathrm{p}} \mathrm{ODN} 2006 \times 3-\mathrm{PD}$ on flake-shell SiO 2 nanoparticles coated with PEI of Mns 600, 1800, and 10,000 were estimated to be 196,364, and $650 \mathrm{pmol} / \mathrm{mL}$ medium, respectively.

Abbreviations: PEl, polyethyleneimine, NPs, nanoparticles; Mn, number-average molecular weight; ODN, oligodeoxynucleotides; IFN- $\alpha$, interferon alpha.

PEI-1800 and PEI-10,000, despite the lower capacity to load CpG ODN2006x3-PD molecules. This effect may be due to two possible reasons, ie, the higher density of $\mathrm{CpG}$ ODN2006x3-PD molecules on the $\mathrm{SiO}_{2}$ nanoparticles coated with PEI-1800 and PEI-10,000 and the higher Mns of the PEI. To evaluate these possibilities, we prepared flake-shell $\mathrm{SiO}_{2}$ nanoparticles coated with PEI at the three different Mns but loaded with the same density of CpG ODN2006x3-PD molecules (about $100 \mu \mathrm{g} / \mathrm{mg}$ nanoparticles, which corresponds to the maximum loading capacity of PEI-600), and examined the level of IFN- $\alpha$ induction. Consequently, the potential to induce IFN- $\alpha$ was significantly lower in PEI-1800 and PEI10,000 (Figure 6), which suggests that the Mn of PEI but not the density of CpG ODN2006x3-PD molecules on flake-shell $\mathrm{SiO}_{2}$ nanoparticles affects IFN- $\alpha$ induction.

To investigate further the cause of lower IFN- $\alpha$ induction by CpG ODN2006x3-PD molecules loaded onto flake-shell $\mathrm{SiO}_{2}$ nanoparticles coated with PEI-1800 and PEI-10,000, we observed the cellular uptake and intracellular localization of CpG ODN2006x3-PD molecules delivered by flakeshell $\mathrm{SiO}_{2}$ nanoparticles with confocal laser fluorescence microscopy. No apparent difference in the cellular uptake of CpG ODN2006x3-PD molecules was observed among flake-shell $\mathrm{SiO}_{2}$ nanoparticles coated with PEI of the three different Mns (Figure 7), which suggests that a difference in cellular uptake is not responsible for the lower IFN- $\alpha$ induction in flake-shell $\mathrm{SiO}_{2}$ nanoparticles coated with PEI-1800 and PEI-10,000. CpG ODN2006x3-PD molecules delivered by flake-shell $\mathrm{SiO}_{2}$ nanoparticles coated with PEI-600 were localized in the cytosol (Figure 7). However, when the $\mathrm{CpG}$ oligodeoxynucleotide molecules were delivered by flake-shell $\mathrm{SiO}_{2}$ nanoparticles coated with PEI-1800 and PEI-10,000, CpG ODN2006x3-PD molecules were observed in the nucleus in some cells, although the molecules were also occasionally localized in the cytosol (Figure 7). The localization of $\mathrm{CpG}$ ODN2006x3-PD molecules in the nucleus and cytosol

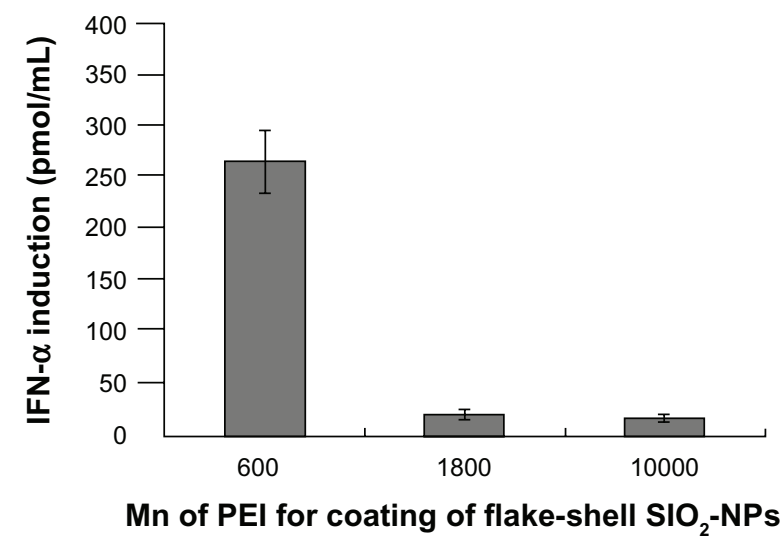

Figure 6 IFN- $\alpha$ induction by the same density of CPG ODN2006 3-PD on flake-shell $\mathrm{SiO} 2$ nanoparticles coated with PEl of Mns 600, 1800, and 10,000. The loading amount of CPG ODN2006×3-PD was about $100 \mu \mathrm{g} / \mathrm{mg}$ nanoparticles $(200 \mathrm{pmol} / \mathrm{mL}$ medium), which is similar to the maximum loading capacity of flake-shell $\mathrm{SiO}_{2}$ nanoparticles coated with PEI of $\mathrm{Mn} 600$. The flake-shell $\mathrm{SiO}_{2}$ nanoparticles loaded with CPG ODN2006×3-PD were applied to peripheral blood mononuclear cells at a concentration of $50 \mu \mathrm{g}$ nanoparticles $/ \mathrm{mL}$. The $\mathrm{SiO}_{2}$ nanoparticles coated with PEI of Mns 1800 and 10,000 showed a significantly lower level of IFN- $\alpha$ induction despite having the same density of $\mathrm{CpG}_{\mathrm{O}} \mathrm{ODN} 2 \mathrm{O06} \times 3-\mathrm{PD}$ as the $\mathrm{SiO}_{2}$ nanoparticles coated with PEI of Mn 600.

Abbreviations: PEl, polyethyleneimine, NPs, nanoparticles; Mn, number-average molecular weight; ODN, oligodeoxynucleotides; IFN- $\alpha$, interferon alpha. 


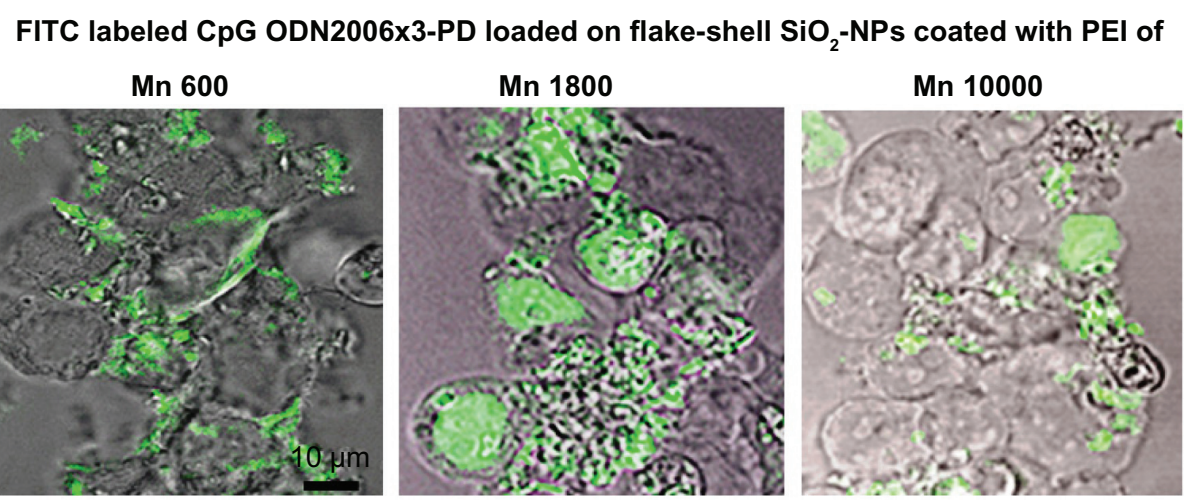

Figure 7 Intracellular localization of CpG ODN2006×3-PD delivered by flake-shell $\mathrm{SiO}_{2}$ nanoparticles coated with PEI of Mns 600, I800, and I0,000. FITC-labeled CPG ODN2006x3-PD was loaded on the $\mathrm{SiO}_{2}$ nanoparticles through PEI.

Notes: The loading amount of FITC-labeled CPG ODN2006x3-PD was approximately $100 \mu \mathrm{g} / \mathrm{mg}$ nanoparticles, and the SiO 2 nanoparticles were applied to the cells at a concentration of $50 \mu \mathrm{g} / \mathrm{mL}$. Each image was obtained from a cross-section of cells using confocal laser fluorescence microscopy. Bar $=10 \mu \mathrm{m}$.

Abbreviations: FITC, fluorescein isothiocyanate; PEl, polyethyleneimine, NPs, nanoparticles; Mn, number-average molecular weight; ODN, oligodeoxynucleotides.

is thought to be caused by the escape of $\mathrm{CpG}$ oligodeoxynucleotide molecules from endolysosomes. Because TLR9, which is a receptor for CpG oligodeoxynucleotide, is localized in the endoplasmic reticulum and transferred to endolysosomes, escape of $\mathrm{CpG}$ oligodeoxynucleotide molecules from endolysosomes is considered to reduce the opportunity for interaction with TLR9.

\section{Discussion}

The most characteristic feature of our flake-shell $\mathrm{SiO}_{2}$ nanoparticles is the large specific surface area provided by the thin flake structure. The structure consists of a special sheet of networked flakes with a thickness of 60-80 nm. The specific surface area of the flake-shell $\mathrm{SiO}_{2}$ nanoparticles was 83 -fold higher than that of smooth-surfaced $\mathrm{SiO}_{2}$ nanoparticles, and is similar to that of mesoporous $\mathrm{SiO}_{2}$ nanoparticles with a similar diameter. ${ }^{22,35,36}$ Such a large surface area makes it possible to load a large amount of nucleic acid drugs on the surface of flake-shell $\mathrm{SiO}_{2}$ nanoparticles.

We used PEI of three different Mns for the surface coating of $\mathrm{SiO}_{2}$ nanoparticles in order to electrostatically bind $\mathrm{CpG}$ oligodeoxynucleotide molecules to the surface of the nanoparticles. The surface charge of the PEI-coated $\mathrm{SiO}_{2}$ nanoparticles was positive, and the positive charge density increased as the Mn of PEI increased. This increase in positive charge density is thought to be the result of abundant amino groups in the high molecular weight PEI. Of note, the cationic charge of PEI has been reported to be responsible for cytotoxicity. ${ }^{28}$ Mesoporous $\mathrm{SiO}_{2}$ nanoparticles coated with $10 \mathrm{kDa}$ PEI show significant cytotoxicity in PANC-1, BxPC3, and HEPA- 1 cells at a concentration of $50 \mu \mathrm{g} / \mathrm{mL} .{ }^{28}$ However, no obvious cytotoxicity was observed for smooth-structured $\mathrm{SiO}_{2}$ nanoparticles and our flake-shell $\mathrm{SiO}_{2}$ nanoparticles coated with PEI-10,000, when they were applied to peripheral blood mononuclear cells at a concentration of $50 \mu \mathrm{g} / \mathrm{mL}$. This difference may be attributable to differences in the sensitivity of various cell types to the cationic charge. We observed slightly higher cytotoxicity for PEI-coated flake-shell $\mathrm{SiO}_{2}$ nanoparticles than PEI-coated smooth-surfaced $\mathrm{SiO}_{2}$ nanoparticles at concentrations of $75 \mu \mathrm{g} / \mathrm{mL}$ and $100 \mu \mathrm{g} / \mathrm{mL}$, which implies that the cytotoxicity is caused by the surface structure of the $\mathrm{SiO}_{2}$ nanoparticles and not the PEI. Although the mechanism by which flake-shell $\mathrm{SiO}_{2}$ nanoparticles show slightly higher toxicity at high concentrations than smooth-surface $\mathrm{SiO}_{2}$ nanoparticles remains unknown, the large surface area of the flake structure may contribute to this difference.

The capacity to load CpG ODN2006x3-PD increased with an increase in the Mn of the PEI used for surface coating. This increase in loading capacity is thought to be attributable to a higher positive charge density. We also observed a higher PEI/silica coverage ratio for PEI-10,000 than for PEI-600 and PEI-1800. However, no differences were observed in the coverage ratios for PEI-600 and PEI-1800, although PEI-1800 had a significantly higher loading capacity than PEI-600. This suggests that the PEI/silica coverage ratio is not involved in the loading capacity of CpG ODN2006x3-PD molecules. The loading capacity of CpG ODN2006x3-PD molecules on flake-shell $\mathrm{SiO}_{2}$ nanoparticles coated with PEI was only 5.8-6.7 times higher than that of smooth-surfaced $\mathrm{SiO}_{2}$ nanoparticles coated with PEI, although the surface area of the flake-shell $\mathrm{SiO}_{2}$ nanoparticles was 83 -fold higher. This effect is thought to be caused by a decrease in the surface area because of the coating of the surface by PEI since the specific surface area after coating with PEI was $11 \%-14 \%$ that of naked flake-shell $\mathrm{SiO}_{2}$ nanoparticles. This reduction in 
surface area may be due to penetration of PEI into the open spaces between flakes. Zhu et $\mathrm{al}^{22}$ prepared prefunctionalized mesoporous $\mathrm{SiO}_{2}$ nanoparticles with a size and specific surface area of about $500 \mathrm{~nm}$ and $423 \mathrm{~m}^{2} / \mathrm{g}$, respectively. The maximum loading capacity of $\mathrm{CpG}$ oligodeoxynucleotide molecules was about $80 \mu \mathrm{g} / \mathrm{mg}$ nanoparticles. This group also reported that the loading capacity of $\mathrm{CpG}$ oligodeoxynucleotide molecules was 30-40 $\mu \mathrm{g} / \mathrm{mg}$ nanoparticles for poly-L-lysine-coated mesoporous $\mathrm{SiO}_{2}$ nanoparticles with a size and specific surface area of 400-500 nm and $680 \mathrm{~m}^{2} / \mathrm{g}$, respectively, but the capacity increased to about $100 \mu \mathrm{g} / \mathrm{mg}$ nanoparticles in a layer-by-layer assembly with $\mathrm{CpG}$ oligodeoxynucleotide molecules and poly-L-lysine. ${ }^{36}$ Although flake-shell $\mathrm{SiO}_{2}$ nanoparticles coated with PEI-600 showed the lowest loading capacity $(97.7 \pm 11.5 \mu \mathrm{g} / \mathrm{mg}$ nanoparticles $)$ among the different Mns of PEI, the loading capacity was still comparable with or higher than that of mesoporous $\mathrm{SiO}_{2}$ nanoparticles. Surface coating by polycations has limited usefulness for mesoporous $\mathrm{SiO}_{2}$ nanoparticles because the polycations bury or cover the mesopores. As described above, PEI can penetrate the open space between flakes, which leads to a reduction in surface area for flake-shell $\mathrm{SiO}_{2}$ nanoparticles. However, it is unlikely that the polycation layer completely buries or covers all the sheet-networked flake structures because the thickness of the flake-structured layer is $60-80 \mathrm{~nm}$. Therefore, our flake-shell $\mathrm{SiO}_{2}$ nanoparticles possess a likely advantage in the capacity for loading nucleic acid drugs relative to mesoporous $\mathrm{SiO}_{2}$ nanoparticles when polycations are used for surface coating.

The CpG ODN2006x3-PD molecules on flake-shell $\mathrm{SiO} 2$ nanoparticles were stable at $4^{\circ} \mathrm{C}$ in phosphate-buffered saline, but the potential to induce IFN- $\alpha$ was decreased by about $50 \%$ after lyophilization (data not shown). This is thought to be due to unstable electrostatic binding after lyophilization.

Class A CpG ODN2216 molecules stimulated IFN- $\alpha$ induction in a dose-dependent manner. Although free $\mathrm{CpG}$ ODN2006x3-PD molecules did not induce IFN- $\alpha$, the CpG oligodeoxynucleotide molecules loaded onto $\mathrm{SiO}_{2}$ nanoparticles coated with PEI induced IFN- $\alpha$. CpG ODN2006x3-PD molecules on flake-shell $\mathrm{SiO}_{2}$ nanoparticles coated with PEI showed higher IFN- $\alpha$ induction than CpG ODN2006x3PD on smooth-surfaced $\mathrm{SiO}_{2}$ nanoparticles coated with PEI, probably because of the higher capacity of flake-shell $\mathrm{SiO}_{2}$ nanoparticles to load the $\mathrm{CpG}$ oligodeoxynucleotide. However, CpG ODN2006x3-PD molecules on flake-shell $\mathrm{SiO}_{2}$ nanoparticles coated with PEI-10,000 showed the lowest level of IFN- $\alpha$ induction among flake-shell $\mathrm{SiO}_{2}$ nanoparticles coated with PEI with different Mns, although these particles had the highest loading capacity for $\mathrm{CpG}$ ODN2006x3-PD molecules. In contrast, the highest level of IFN- $\alpha$ production was observed for PEI-600, although the flake-shell $\mathrm{SiO}_{2}$ nanoparticles coated with PEI-600 had the lowest loading capacity. In addition, flake-shell $\mathrm{SiO}_{2}$ nanoparticles coated with PEI-600 showed a much higher level of IFN- $\alpha$ induction than those coated with PEI-1800 and PEI-10,000, even under conditions in which the density of the CpG ODN2006x3-PD molecules was equal among the flake-shell $\mathrm{SiO}_{2}$ nanoparticles coated with PEI of three different Mns. These results suggest that the Mn of the PEI coated on the nanoparticles is a critical factor for IFN- $\alpha$ induction by $\mathrm{CpG}$ oligodeoxynucleotides. Furthermore, we found that the cellular uptake of CpG ODN2006x3-PD molecules loaded onto flake-shell $\mathrm{SiO}_{2}$ nanoparticles was not significantly affected by the Mn of PEI. This observation also suggests that the hydrodynamic size of the flake-shell $\mathrm{SiO}_{2}-\mathrm{NP}$, as determined by the $\mathrm{Mn}$ of PEI, did not affect cellular uptake. Therefore, the Mn and not the uptake of PEI is thought to affect the induction of IFN- $\alpha$.

The results of this study suggest that the Mn of PEI but not the Mn-dependent density of CpG oligodeoxynucleotide molecules on flake-shell $\mathrm{SiO}_{2}$ nanoparticles affects IFN- $\alpha$ induction. PEI is one of the most studied polycations for gene delivery. PEI with a high $\mathrm{Mn}(>10 \mathrm{kDa})$ has a high transfection efficiency, ${ }^{37-39}$ whereas PEI with a low $\mathrm{Mn}(<5 \mathrm{kDa})$ has a low transfection efficiency. ${ }^{39,40}$ For expression of the gene delivered, the gene has to escape from the endosome and be transferred into the nucleus. The high transfection efficiency of high molecular weight PEI is thought to be caused by facilitation of endosomal escape by the proton sponge effect. ${ }^{41-45}$ In contrast with conventional gene delivery, maintaining the presence of $\mathrm{CpG}$ oligodeoxynucleotides in the endolysosomes is necessary for delivery of these molecules because TLR9 is localized in the endolysosomes. Therefore, endosomal escape is not required for $\mathrm{CpG}$ oligodeoxynucleotide delivery. Flake-shell $\mathrm{SiO}_{2}$ nanoparticles coated with PEI-1800 and PEI-10,000 showed a lower potential for IFN- $\alpha$ induction than those coated with PEI-600, despite having a higher loading capacity of $\mathrm{CpG}$ oligodeoxynucleotide molecules. We observed the presence of CpG ODN2006x3PD molecules in the nucleus in some cells, but not in all cells, when the $\mathrm{CpG}$ oligodeoxynucleotide molecules were delivered by flake-shell $\mathrm{SiO}_{2}$ nanoparticles coated with PEI-1800 and PEI-10,000. This finding suggests that destabilization of the endolysosome membrane by the proton sponge effect may be responsible for lower IFN- $\alpha$ production by nanoparticles 
coated with PEI-1800 and PEI-10,000. However, the CpG ODN2006x3-PD molecules were not localized in the nucleus in all cells, which may also have resulted in markedly lower IFN- $\alpha$ induction by nanoparticles coated with PEI-1800 and PEI-10,000.

Petersen et $\mathrm{al}^{46}$ reported that complexes of DNA and PEI with a molecular weight of $800 \mathrm{Da}$ form particles with a size of about $700 \mathrm{~nm}$, while the sizes were about $450 \mathrm{~nm}$ and $90 \mathrm{~nm}$ for complexes of DNA and PEI with molecular weights of $2 \mathrm{kDa}$ and $25 \mathrm{kDa}$, respectively. Weaker ethidium bromide fluorescence was also observed for complexes of DNA and $2 \mathrm{kDa}$ PEI than for DNA and 800 Da PEI because DNA condensation makes it more difficult for ethidium bromide to intercalate with DNA complexed with $2 \mathrm{kDa}$ PEI. These results suggest that PEI with a molecular weight of $800 \mathrm{Da}$ cannot condense DNA efficiently. ${ }^{46}$ Furthermore, Sun et $\mathrm{al}^{47}$ reported that a high protonation ratio of the amino groups in PEI results in the formation of more stable complexes with DNA, but the degree of branching has lesser effect on DNA binding. The higher IFN- $\alpha$ production by flake-shell $\mathrm{SiO}_{2}$ nanoparticles coated with PEI-600 is likely caused by increased affinity of $\mathrm{CpG}$ oligodeoxynucleotide molecules for TLR9, which results from the loose condensation of CpG oligodeoxynucleotide molecules. In contrast, PEI-1800 and PEI-10,000 bind CpG oligodeoxynucleotide molecules more tightly because of their higher positive charge density, which might make it difficult for $\mathrm{CpG}$ oligodeoxynucleotide molecules to interact with TLR9.

\section{Conclusion}

We prepared flake-shell $\mathrm{SiO}_{2}$ nanoparticles with a specific surface area similar to that of mesoporous $\mathrm{SiO}_{2}$ nanoparticles for class B CpG oligodeoxynucleotide delivery. For loading negatively charged $\mathrm{CpG}$ oligodeoxynucleotide molecules, the surface of the nanoparticles was coated with PEI of Mns 600, 1800, and 10,000. The loading capacity of the CpG oligodeoxynucleotide molecules depended on the Mn of PEI, which affected the positive charge density on the surface. Although the flake-shell $\mathrm{SiO}_{2}$ nanoparticles coated with PEI of Mn 600 showed the lowest loading capacity, these flake-shell $\mathrm{SiO}_{2}$ nanoparticles showed the highest IFN- $\alpha$ induction among the three different types of PEI used for surface coating. In addition, higher IFN- $\alpha$ production was observed for $\mathrm{CpG}$ oligodeoxynucleotide molecules on flake-shell $\mathrm{SiO}_{2}$ nanoparticles coated with PEI of Mn 600, even when the density of $\mathrm{CpG}$ oligodeoxynucleotide molecules was the same among the nanoparticles coated with PEI of three different Mns. The flake-shell $\mathrm{SiO}_{2}$ nanoparticles showed a higher potential for $\mathrm{CpG}$ oligodeoxynucleotide delivery than smooth-surfaced $\mathrm{SiO}_{2}$ nanoparticles, and the use of PEI of Mn 600 for the surface coating to load CpG oligodeoxynucleotide molecules resulted in significantly increased IFN- $\alpha$ induction. This higher level of IFN- $\alpha$ induction is believed to be attributable to the residence of the $\mathrm{CpG}$ oligodeoxynucleotide molecules in endolysosome.

\section{Acknowledgments}

This work was supported by Grants-in-Aid for Scientific Research (C-22560777 and 23/01510) from the Japan Society for the Promotion of Science and the Ministry of Education, Culture, Sports, Science, and Technology.

\section{Disclosure}

The authors report no conflicts of interest in this work.

\section{References}

1. Fonseca DE, Kline JN. Use of CpG oligonucleotides in treatment of asthma and allergic disease. Adv Drug Deliv Rev. 2009;61:256-262.

2. Salem AK, Weiner JG. CpG oligonucleotides as immunotherapeutic adjuvants: innovative applications and delivery strategies. Adv Drug Deliv Rev. 2009;61:193-194.

3. Vollmer J, Kreig AM. Immunotherapeutic applications of $\mathrm{CpG}$ oligodeoxynucleotide TLR9 agonists . Adv Drug Deliv Rev. 2009;61:195-204.

4. Zhou S, Kawakami S, Yamashita F, Hashida M. Intranasal administration of CpG DNA lipoplex prevents pulmonary metastasis in mice. Cancer Lett. 2010;287:75-81.

5. Hornung V, Rothenfusser S, Britsch S, et al. Quantitative expression of Toll-like receptor 1-10 mRNA in cellular subsets of human peripheral blood mononuclear cells and sensitivity to $\mathrm{CpG}$ oligonucleotides. J Immunol. 2002;168:4531-4537.

6. Weiner GJ, Liu HM, Wooldridge JE, Dahle CE, Krieg AM. Immunostimulatory oligonucleotides containing the $\mathrm{CpG}$ motif are effective as immune adjuvants in tumor antigen immunization. Proc Natl Acad Sci U S A. 1997;94:10833-10837.

7. Bauer S, Kirschning CJ, Hacker H, et al. Human TLR9 confers responsiveness to bacterial DNA via species-specific $\mathrm{CpG}$ motif recognition. Proc Natl Acad Sci U SA. 2001;98:9237-9242.

8. Verthelyi D, Ishii KJ, Gursel M, Takeshita F, Klinmann DM. Human peripheral blood cells differentially recognize and respond to two distinct CpG motifs. J Immunol. 2001;166:2372-2377.

9. Kerkmann M, Costa LT, Richter C, et al. Spontaneous formation of nucleic acid-based nanoparticles is responsible for high interferon- $\alpha$ induction by CpG-A in plasmacytoid dendritic cells. $J$ Biol Chem. 2005;280:8086-8093.

10. Klein DCG, Latz E, Espevik T, Stokke BT. Higher order structure of short immunostimulatory oligonucleotides studied by atomic force microscopy. Ultramicroscopy. 2010;110:689-693.

11. Krug A, Rothenfusser S, Hornung V, et al. Identification of $\mathrm{CpG}$ oligonucleotide sequences with high induction of IFN-alpha/beta in plasmacytoid dendritic cells. Eur J Immunol. 2001;31:2154-2163.

12. Krieg AM. CpG motifs in bacterial DNA and their immune effects. Annu Rev Immunol. 2002;20:709-760.

13. Gürsel M, Verthelyi D, Gürsel I, Ishii KJ, Klinman DM. Differential and competitive activation of human immune cells by distinct classes of CpG oligonucleotide. J Leukoc Biol. 2002;71:813-820.

14. Hartmann G, Weeratna RD, Ballas ZK, et al. Delineation of a $\mathrm{CpG}$ phosphorothioate oligodeoxynucleotide for activating primate immune responses in vitro and in vivo. J Immunol. 2000;164:1617-1624. 
15. Hartmann G, Krieg AM. Mechanism and function of a newly identified CpG DNA motif in human primary B cells. J Immunol. 2000;164:944-953.

16. Krug A, Towarowski A, Britsch S, et al. Toll-like receptor expression reveals $\mathrm{CpG}$ DNA as a unique microbial stimulus for plasmacytoid dendritic cells which synergizes with CD40 lignd to induce high amount of IL-12. Eur J Immunol. 2001;31:3026-3037.

17. Sheehan JP, Lan HC. Phosphorothioate oligonucleotides inhibit the intrinsic tenase complex. Blood. 1998;92:1617-1625.

18. Brown DA, Kang SH, Gryaznov SM, et al. Effect of phosphorothioate modification of oligodeoxy-nucleotides on specific protein binding. J Biol Chem. 1994;269:26801-26805.

19. Levin AA. A review of the issues in the pharmacokinetics and toxicology of phosphorothioate antisense of oligonucleotides. Biochim Biophys Acta. 1999;1489:69-84.

20. Henry SP, Beattie G, Yeh G, et al. Comlement activation is responsible for acute toxicities in rhesus monkeys treated with a phosphorothioate oligonucleotide. Int Immunopharmacol. 2002;2:1657-1666.

21. Meng W, Yamazaki T, Nishida Y, Hanagata N. Nuclease-resistant immunostimulatory phosphodiester $\mathrm{CpG}$ oligodeoxynucleotides as human Toll-like receptor 9 agonists. BMC Biotechnol. 2011;11:88-96.

22. Zhu Y, Meng W, Li X, Gao H, Hanagata N. Design of mesoporous silica/cytosine-phosphodiester-guanin oligodeoxynucleotide complexes to enhance delivery efficiency. J Phys Chem C. 2011;115:447-452.

23. Zhi C, Meng W, Yamazaki T, et al. BN nanospheres as CpG ODN carriers for activation of toll-like receptor 9. J Mater Chem. 2011;21: 5219-5222.

24. Wilson KD, Susan DJ, Tam YK. Lipid-based delivery of CpG oligonucleotides enhances immunotherapeutic efficacy. Adv Drug Deliv Rev 2009;61:233-242.

25. Bourquin C, Anz D, Zwiorek K, et al. Targeting CpG oligonucleotides to the lymph node by nanoparticles elicits efficient antitumoral immunity. J Immunol. 2008;181:2990-2998.

26. Kuramoto Y, Kawakami S, Zhou S, Fukuda K, Yamashita F, Hashida M. Use of mannosylated cationic liposomes/immunostimulatory CpG DNA complex for effective inhibition of peritoneal dissemination in mice. J Gene Med. 2008;10:392-399.

27. Chen $\mathrm{X}, \mathrm{Wu} \mathrm{P}$, Rousseas $\mathrm{M}$, et al. Boron nitride nanotubes are noncytotoxic and can be functionalized for interaction with proteins and cells. J Am Chem Soc. 2009;131:890-891.

28. Xia T, Kovochich M, Liong M, et al. Polyethyleneimine coating enhances the cellular uptake of mesoporous silica nanoparticles and allows safe delivery of siRNA and DNA constructs. ACS Nano. 2009;3:3273-3286.

29. Hom C, Lu J, Liong M, et al. Mesoporous silica nanoparticles facilitate delivery of siRNA to shutdown signaling pathways in mammalian cells. Small. 2010;6:1185-1190.

30. Chen AM, Zhang M, Wei D, et al. Co-delivery of doxorubicin and Bcl-2 siRNA by mesoporous silica nanoparticles enhances the efficacy of chemotherapy in multidrug-resisitant cancer cells. Small. 2009;5: 2673-2677.

31. Ji Q, Guo C, Yu X, et al. Flake-shell capsules: adjustable inorganic structures. Small. May 7, 2012. [Epub ahead of print.]
32. Park IY, Kim IY, Yoo MK, Choi YJ, Cho MH, Cho CS. Mannosylated polyethyleneimine coupled mesoporous silica nanoparticles for receptor-mediated gene delivery. Int J Pharm. 2008;359:280-287.

33. Elbakry A, Zaky A, Liebl R, Rachel R, Geopferich A, Breunig M. Layer-by-layer assembled gold nanoparticles for siRNA delivery. Nano Lett. 2009;9:2059-2064.

34. McBain SC, Yiu HHP, Haj AE, Dobson J. Polyethyleneimine functionalized iron oxide nanoparticles as agents for DNA delivery and transfection. J Mater Chem. 2007;17:2561-2565.

35. Zhu Y, Meng W, Hanagata N. Cytosine-phosphodiester-guanin oligodeoxynucleotide ( $\mathrm{CpG}$ ODN)-capped hollow mesoporous silica particles for enzyme-triggered drug delivery. Dalton Trans. 2011;40: 10203-10208.

36. Zhu Y, Meng W, Gao H, Hanagata N. Hollow mesoporous silica/poly(Llysine) particles for codelivery of drug and gene with enzyme-triggered release property. J Phys Chem C. 2011;115:13630-13636.

37. Fischer D, Bieber T, Li YX, Elsasser HP, Kissel T. A novel non-viral vector for DNA delivery based on low molecular weight, branched polyethylenimine: effect of molecular weight on transfection efficiency and cytotoxicity. Pharm Res. 1999;16:1273-1279.

38. Godbey WT, Wu KK, Mikos AG. Size matters: molecular weight affects the efficiency of poly(ethylenimine) as a gene delivery vehicle. J Biomed Mater Res. 1999;45:268-275.

39. Kunath K, von Harpe A, Fischer D, et al. Low-molecular-weight polyethylenimine as a non-viral vector for DNA delivery: comparison of physicochemical properties, transfection efficiency and in vivo distribution with high-molecular-weight polyethylenimine. J Control Release. 2003;89:113-125.

40. Wang CF, Lin YX, Jiang T, He F, Zhuo RX. Polyethylenimine-grafted polycarbonates as biodegradable polycations for gene delivery. Biomaterials. 2009;30:4824-4832.

41. Godbey WT, Wu KK, Mikos AG. Tracking the intracellular path of poly(ethylenimine)/DNA complexes for gene delivery. Proc Natl Acad Sci USA. 1999;96:5177-5181.

42. Boussif O, Lezoualc'h F, Zanta MA, et al. A versatile vector for gene and oligonucleotide transfer into cells in culture and in vivo: polyethylenimine. Proc Natl Acad Sci US A. 1995;92:7279-7301.

43. Sonawane ND, Szoka FC, Verkman AS. Chloride accumulation and swelling in endosomes enhances DNA transfer by polyamine-DNA J Biol Chem. 2003;278:44826-44831.

44. Haensler J, Szoka FC. Polyamidoamine cascade polymers mediate efficient transfection of cells in culture. Bioconjug Chem. 1993;4:372-379.

45. Behr JP. Gene transfer with synthetic cationic amphiphiles: prospects for gene therapy. Bioconjug Chem. 1994;5:382-389.

46. Petersen H, Kunath K, Martin AL, et al. Star-shaped poly(ethylene glycol)-block-polyethylenimine copolymers enhance DNA condensation of low molecular weight polyethylenimines. Biomacromolecules. 2002;3:926-936

47. Sun C, Tang T, Uludag H, Cuervo JE. Molecular dynamics simulations of DNA/PEI complexes: Effect of PEI branching and protonation state. Biophys J. 2011;100:2754-2763.
International Journal of Nanomedicine

\section{Publish your work in this journal}

The International Journal of Nanomedicine is an international, peerreviewed journal focusing on the application of nanotechnology in diagnostics, therapeutics, and drug delivery systems throughout the biomedical field. This journal is indexed on PubMed Central,

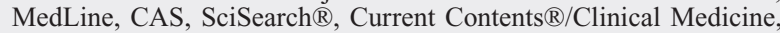

\section{Dovepress}

Journal Citation Reports/Science Edition, EMBase, Scopus and the Elsevier Bibliographic databases. The manuscript management system is completely online and includes a very quick and fair peer-review system, which is all easy to use. Visit http://www.dovepress.com/ testimonials.php to read real quotes from published authors. 